\title{
Entrevista - Gonzalo de Amézola Esquizohistoria: a complexidade das relações entre a História produzida pelos historiadores e aquela ensinada nas escolas de Educação Básica
}

\begin{abstract}
Esquizohistoria: the complex relationship between History produced by historians and that taught in Basic Education
\end{abstract}

Maria Aparecida Lima dos Santos*

Patrícia Bastos de Azevedo**

\section{RESUmo}

A entrevista com o professor e pesquisador Dr. Gustavo de Amézola, docente de Prática de Ensino de História na Universidade de La Plata (UNLP), Argentina, foi realizada com o objetivo de divulgar sua reflexão em torno das questões que, historicamente, marcaram as relações entre a História produzida nas universidades e aquela gestada na sala de aula. A partir de seu livro intitulado Esquizohistoria: la historia que se enseña en la escuela, la que preocupa a los historiadores y una renovación posible de la historia escolar, foram abordados temas relacionados à história da disciplina de História e sua imbricação com a historiografia e com as práticas políticas dos governantes de seu país. Também foram enfocados a temática da formação de professores, as reformas do sistema educativo argentino nas duas últimas décadas e os principais aspectos que, do seu ponto de vista, constituem-se como desafios para o ensino de História na contemporaneidade.

Palavras-chave: esquizohistoria; ensino de História; disciplina escolar.

\section{Abstract}

The interview with Dr. Gustavo de Amézola, professor and researcher of History teaching practice at the University of La Plata (UNLP), Argentina, was carried out in order to disclose their reflection on issues that have historically marked relations between History produced in universities and that gestated in the classroom. From his book entitled Esquizohistoria: la historia que se enseña en la escuela, la que preocupa a los historiadores y una renovación posible de la historia escolar, topics were discussed related to the history of discipline and its overlapping with the historiography and political practices of the rulers of his country. Also were focused on the theme of teacher education, reforms of the Argentine education system in the last two decades and the main aspects, which in its view, constitute as challenges to the teaching of history nowadays.

Keywords: esquizohistoria; teaching History; school subject.

\footnotetext{
* Doutora em Educação. Professora de Prática de Ensino de História e Estágio Supervisionado, Universidade Federal de Mato Grosso do Sul (UFMS). Campo Grande, MS, Brasil. maria.limasantos@ufms.br

** Doutora em Educação. Professora da área de Ensino de História, Universidade Federal Rural do Rio de Janeiro (UFRRJ). Seropédica, RJ, Brasil. patriciabazev@gmail.com
} 
Nesta entrevista com o prof. Dr. Gonzalo de Amézola, docente da Universidad Nacional de La Plata (UNLP), exploramos alguns dos aspectos em torno do que chamou de esquizohistoria, termo mobilizado no contexto de suas reflexões sobre as relações entre o conhecimento histórico acadêmico e o conhecimento histórico escolar, cuja complexidade pode ser compreendida no longo processo de configuração da disciplina escolar de História. Consideramos que seus apontamentos são relevantes por mobilizar referenciais teóricos tanto da História, quanto da Educação, trabalhando nesse lugar de fronteiras que caracteriza, cada vez com mais intensidade e densidade, o campo de pesquisas e práticas em ensino de História.

Além disso, o prof. Amézola apresenta um panorama histórico do processo de constituição da disciplina na Argentina, destacando como uma tradição de memorismo e nacionalismo, que marcam a prática docente naquele país até a atualidade, foi instaurada ao longo dos séculos XIX e XX na História ensinada, em uma perspectiva cada vez mais autoritária. Destaca momentos-chave em que a narrativa veiculada nas escolas foi controlada de perto pelos governantes que, em meio a combates públicos pela História, impunham os fatos que deveriam figurar nos currículos.

A dimensão política do ensino de História é ressaltada por Amézola em seu relato dos mecanismos institucionais através dos quais se instaurou o mito de origem da Nação argentina, em cujo cerne um sentido comum histórico foi gestado. No ponto de partida da nacionalidade argentina figurava o futuro inevitável de grandeza em torno do qual se configurou um panteão de heróis, que, durante muito tempo, instituiu o sentido principal da História ensinada. Esses "homens extraordinários" foram rotulados de próceres ou "bandidos" de acordo com o resultado do duelo público entre "história oficial" e revisionistas.

No quadro que configura, destaca-se o intenso debate em torno dos conteúdos a serem inseridos nos currículos de formação de professores de História no interior dos cursos de graduação na Argentina, elemento diretamente relacionado, a seu entender, com algumas permanências identificadas na História ensinada. Nesse sentido, apresenta alguns dados recentes da realidade do Ensino Superior naquele país, abordando os pontos fundamentais das discussões travadas em torno dos currículos de licenciatura.

Mesmo frente à instabilidade política argentina a partir da década de 1950, e da dura repressão sofrida pela população entre 1976 e 1983, sob a ditadura 
civil-militar que lá se instalou, o ensino de História seguiu cumprindo um papel disciplinador em meio a embates pela memória e combates pela História, os quais se intensificaram ao longo das duas últimas décadas no contexto das chamadas reformas do sistema educativo.

O depoimento do prof. Amézola nos traz muitos elementos para refletir sobre o ensino de História no Brasil, tanto pelas semelhanças na história da disciplina, quanto, principalmente frente à derrocada de movimentos de criminalização da prática docente e de uma "guinada conservadora" que marca o cenário político atual em nosso país.

Convidamos o(a) leitor(a) a apreciar conosco o conteúdo dessa entrevista, que traz, implicitamente, um desafio que nos é comum: como ensinar História no século XXI?

As organizadoras

Gonzalo de Amézola é professor titular de "Planificación didáctica y prácticas de la enseñanza” na Universidad Nacional de La Plata (UNLP), onde também é pesquisador. Nessa qualidade, coordena na Argentina o projeto "Jovens e a História no Mercosul”, cuja coordenação geral é do prof. Dr. Luis Fernando Cerri (Universidade Estadual de Ponta Grossa - UEPG/PR). Atualmente, é diretor do Mestrado em Ensino de História da Universidad Nacional de Tres de Febrero e editor de Clío \& Asociados. La historia enseñada, revista especializada que existe desde 1996 e é coeditada pela Universidad Nacional del Litoral (UNL) e pela UNLP.

¿En qué contexto y cuáles fueron las motivaciones que lo llevaron a elaborar el término 'esquizohistoria', que usted presenta en su libro de 2008? ¿Cuál es su significado y por qué lo considera importante para pensar las relaciones entre la Historia producida por los historiadores y la que se enseña en las escuelas de Educación Básica?

Como comento en la presentación del libro, el término de "esquizohistoria” surge de un problema práctico del que hablábamos casi veinticinco años atrás con una colega mientras trabajábamos en otro artículo. En estas circunstancias conversábamos sobre nuestros alumnos de la carrera de Historia de la 
Universidad Nacional de La Plata, que ella recibía ni bien ingresaban en su cátedra de "Introducción a la Historia" y yo veía salir de "Planeamiento didáctico y prácticas de la enseñanza", cuando estaban a punto de graduarse como profesores. En ese diálogo nos llamaba la atención la magnitud de las contradicciones entre la visión del pasado que traían los jóvenes de su educación secundaria y la que se les presentaba en la Facultad, a la vez que notábamos una dificultad similar cuando estos estudiantes estaban por terminar su carrera y debían retornar a la escuela como docentes. Para nosotros, eso no se trataba de un problema de más o menos erudición sino de una cuestión relacionada con la incapacidad de nuestra disciplina para enseñar a pensar a los alumnos secundarios por dos motivos: por un lado, porque la Historia se había transformado en un conocimiento especializado, lo que dificultaba la definición de una nueva historia escolar y, por otro, porque la escuela obturaba toda innovación con los preceptos y rutinas que se ocupaba de eternizar en las aulas. De estas conversaciones surgió un artículo ("Esquizohistoria e historiofrenia. Del secundario a la carrera de historia y de vuelta al secundario") que presentaba este problema y tuvo una repercusión bastante considerable en el ambiente de quienes estaban preocupados por la enseñanza de la historia. Sin duda, mucho mayor que la del artículo original que había provocado nuestras disquisiciones sobre la enseñanza, razón por la cual nos dimos cuenta que ese problema que nosotros percibíamos en nuestros estudiantes estaba mucho más generalizado de lo que creíamos. Cuando en 2008 estaba a punto de publicar el libro, otra colega me sugirió que exhumara aquel viejo título y así fue como reapareció.

Como dije, no hay una elaboración teórica detrás del término de "esquizohistoria" sino una especie de boutade. Si vulgarmente se entiende a la esquizofrenia como la patología por la cual un individuo presenta una disociación entre sus funciones psíquicas, una falta de concordancia entre sus impresiones sensoriales y las reacciones provocadas por ellas, entre sus ideas y sus emociones, nosotros queríamos graficar con el término "esquizohistoria" una situación análoga que se producía entre la Historia que preocupaba a los investigadores y la que se enseñaba en la escuela. Pensábamos que esa fractura era patológica porque para que la Historia resultara significativa era necesario que se apartara de la exaltación de las epopeyas patrióticas que habían perdido todo sentido en la formación de los jóvenes y se la reemplazara por una perspectiva que introdujera en alguna medida el potencial que tiene esta disciplina para enseñar a pensar y entender el mundo. 
Poco después de la aparición de ese artículo original comenzó en Argentina un proceso de reforma educativa que se propuso renovar totalmente la educación en general, incluyendo a la enseñanza de la historia. En realidad, desde 1993 esos cambios son permanentes y lo único estable desde entonces en la educación argentina es esa perpetua renovación, a la vez que para la opinión pública la educación empeora a pesar de los distintos criterios que se impulsan para modernizarla.

En su texto Usted anota que las preocupaciones por analizar históricamente cómo se estableció en la escuela una visión tan resistente a los cambios es algo que ha aumentado en los últimos años. Destaca, a partir de Raimundo Cuesta, que tal resistencia se debe, entre una serie de factores, a la existencia de un "código disciplinar".

Raimundo Cuesta estudió cómo se fue formando la historia escolar en su país a través del tiempo con una visión vinculada con la historia social de la cultura. Dos de sus obras me impresionaron: sobre todo Sociogénesis de una disciplina escolar: la Historia (Pomares - Corredor, 1997) pero también Clío en las aulas. La enseñanza de la Historia en España entre reformas, ilusiones y rutinas (Akal, 1998). Para Cuesta, a diferencia de los estudios tradicionales, la historia escolar presenta una independencia casi total de su ciencia referente. Sostiene que más que comprobar (que también ha de hacerse) el grado de adaptación entre el ritmo de innovación científica y su aplicación didáctica, habría que estudiar el conjunto de agentes sociales que filtran y dan nuevo significado y 'recontextualizan' las materias de enseñanza. Plantea también que la dinámica de transmutación de significado cultural y social de las disciplinas no podría buscarse exclusivamente en los programas de estudio, o en los libros de texto, o en la evolución de las ideas pedagógicas, sino en el ámbito más inaccesible y misterioso de las prácticas de enseñanza.

Un concepto clave en el análisis de Cuesta es el de código disciplinar, al que define como el conjunto de ideas, valores, suposiciones, reglamentaciones y rutinas prácticas (de carácter expreso y tácito) que a menudo se traducen en discursos legitimadores y lenguajes públicos sobre el valor educativo de la Historia, y que orientan la práctica profesional de los docentes. En suma, el elenco de ideas, discursos y prácticas dominantes en la enseñanza de la Historia 
dentro del marco escolar. Este "código disciplinar" se sintetiza para el autor en el caso español en tres características: elitismo, memorismo y nacionalismo.

De la noción de "código disciplinar" se desprende su distinción entre "historia reglamentada", "historia soñada" e "historia enseñada". La primera categoría incluye las normas y disposiciones que regulan a la enseñanza, donde tienen especial relevancia los planes de estudio y los manuales escolares, en una definición que no difiere sustancialmente de la tradicional de "currículum explícito". Más perturbador es el concepto de "historia soñada", con el que Cuesta califica lo que para él es una tradición de crítica utópica que procura modificar las reglamentaciones con argumentos que se repiten en el caso español desde fines del siglo XIX, ya que da por iniciada esa corriente con las ideas de Rafael Altamira. Para el autor se trata de una tradición tan bienintencionada como ingenua e impotente porque la impugnación de lo existente y la voluntad de cambio no se sostienen sobre bases firmes. Se trata para él de una crítica inconducente. Entre la "reglamentada" y la "soñada" se despliega efectivamente en las aulas la "historia enseñada", un campo caracterizado por las prácticas instituidas, las rutinas y los conocimientos admitidos por la escuela. La "historia enseñada" es según Cuesta un tipo de racionalización de la conducta habitual, sustentada en ideas de baja intensidad intelectual, y no siempre conscientes, sobre el conocimiento escolar y su enseñanza, pero de gran eficacia para la buena marcha de la función social de ser profesor y de hacer de profesor. Los docentes, afirma, han tenido originalmente una formación académica exigente pero luego han sido devorados por la rutina y resulta característico su rechazo de las teorías que intentan explicar o guiar su práctica. Sostiene, finalmente, que se trata de una profesión profundamente apegada al prejuicio que idealiza la acción en el aula como principal y casi exclusiva referencia profesional.

Este análisis es muy interesante y esclarecedor de mucho de lo que ocurre en las aulas y tiene, en mi opinión, muchos puntos de contacto con el caso argentino. Si volvemos al "código disciplinar", de las tres características con las que Cuesta resume el caso español, para Argentina el único que podría discutirse es el elitismo porque a lo largo del siglo XX la educación secundaria se expandió en forma constante con algunos momentos especialmente intensos, como los dos primeros gobiernos de Perón. Tal vez, lo que deberíamos discutir en este caso son las formas como se da el elitismo en mi país o las vías 
por las que ese fenómeno se produce a pesar de la expansión de la matrícula. El memorismo y el nacionalismo son indiscutibles, pero en lo que hace a este último fenómeno, creo que en Argentina el nacionalismo fue mutando para aliarse de una forma cada vez más estrecha con el paso del tiempo con una perspectiva muy autoritaria.

La instauración de una "Historia General" que narraba el "nacimiento" de la nación en el siglo XIX marcó a la historiografía de aquel período y también a la enseñanza escolar de la Historia en el Brasil. ¿Cómo se instaló en la Argentina el estudio de la Historia en la escuela y cuáles fueron las principales características de la enseñanza de la historia a lo largo de ese período?

A mediados del siglo XIX, la polifacética figura de Bartolomé Mitre - político, militar, poeta, periodista, traductor del Dante, fundador de nuestra historia científica y presidente de la nación entre 1862 y 1868, años en que se comenzó a trazar el Estado moderno y el modelo de economía agroexportadora - definió el origen de la nacionalidad, estableció qué eran los "argentinos" a partir de la invención y difusión de una conciencia nacional antes inexistente y, finalmente, señaló cuál era el destino de nuestro país. Aunque la suya no fue la única influencia, considero que fue la más importante. Su concepto de Nación quedó definitivamente fijado en la enseñanza y se organizó el panteón de los héroes según su criterio, que tenía como figura máxima al General San Martín y como excluido al "tirano" Juan Manuel de Rosas, quien fuera desde 1829 el autoritario gobernador de Buenos Aires, al que una coalición de fuerzas integrada por los ejércitos de las provincias argentinas, Uruguay, Brasil y los emigrados políticos - entre los cuales estaba Mitre - derrotó en 1852 en la batalla de Caseros. Dos elementos de su narración del pasado le aseguraron éxito en las aulas. El primero de ellos fue su estilo, que aunaba una redacción historiográfica erudita con la creación de efectos dramáticos que facilitaban su utilización escolar. El segundo, que su visión de la historia argentina soldaba el pasado al presente y, sobre todo, a un porvenir donde nos aguardaba un inevitable destino de grandeza. Lo que Ortega y Gasset calificó años más tarde como "el incurable mito de los argentinos".

A partir de fines del siglo XIX y, sobre todo, hacia 1910 - cuando cumplía su primer centenario - la Revolución de Mayo, el momento en que Mitre había establecido el "nacimiento" de la Nación - se instaló definitivamente en el 
sentido común histórico como el punto de partida de la nacionalidad y también como el centro de su carácter republicano e independentista, superando las controversias que esa elección había ocasionado. Además, pasó a considerársela como un movimiento uniforme, sin mayores conflictos internos, a cargo de hombres que - frente a las intenciones disgregadoras que le atribuía a los caudillos - nunca imaginaron otra alternativa política que formar una nación, y que conocían el destino glorioso que les aguardaba al final del camino. Aún cien años después, en los festejos del Bicentenario, el gobierno de la presidente Kirchner, que procuró presentar una visión contestataria o, al menos, no convencional del pasado, en ningún momento puso en duda aquel exitoso mito de los orígenes.

Un elemento fundamental del relato mitrista que caló hondo en las aulas fue el del papel de los héroes: un puñado de hombres extraordinarios en quienes se encarnaban las ideas de emancipación. Sin embargo, Juan Bautista Alberdi ya había hecho notar la particularidad de que ese panteón presentaba el peligro de estar superpoblado de militares. Promover la emulación de los próceres fue el sentido principal que tuvo la enseñanza de la historia argentina en las aulas primarias y secundarias por más de un siglo.

Una segunda etapa de esta educación nacionalista se abre en 1930. Para ese entonces, el modelo económico basado en la exportación de carne y cereales había recibido los embates de la crisis mundial de 1929, y la profecía de la inevitable grandeza argentina que anunciara Mitre parecía irrealizable. Para un sector de la sociedad de ideas conservadoras, los problemas que se habían desatado no eran otra cosa que la manifestación de los vicios de la democracia que una reforma electoral había hecho posible desde 1916. Por otra parte, los partidarios de una nación "esencial” reaparecieron en el debate público con el agregado de características acordes con el autoritario nacionalismo europeo. Como en el siglo XIX, proponían la afirmación de la nacionalidad a partir de rasgos de la herencia hispánica pero agregaban ahora el desprecio por la democracia "formal" respetuosa del parlamentarismo y la división de poderes, y exaltaban una democracia "sustancial" que entendía a la nación como unidad homogénea y monolítica.

La polémica política se convirtió enseguida en un combate por la Historia. Si la ilusión acerca de la grandeza de la Argentina no se había concretado en un país asolado por la crisis, los nacionalistas se propusieron revisar lo que 
calificaron como la "historia falsificada" y forjaron un mito simétrico: había que buscar en el pasado a los culpables de que ese destino no se concretara y simultáneamente reivindicar a los injustamente condenados. En esta lucha no objetaban el lugar que se le había asignado a José de San Martín como Padre de la Patria y arquetipo de todas las virtudes del hombre argentino, pero procuraron reivindicar a los caudillos provinciales hasta entonces condenados como enemigos de la patria por la historia escrita por sus vencedores y, especialmente, a Juan Manuel de Rosas a quien consideraban como el defensor de la soberanía nacional ante la agresión extranjera y no el tirano sangriento que describiera lo que llamaban la "historia falsificada".

En esta confrontación, incluían a la historia escolar porque la consideraban una de las principales usinas desde donde se difundía ese fraude histórico. Pero lo más significativo para la enseñanza de la historia no estuvo vinculado al reemplazo de unos héroes por otros sino a una reinterpretación en clave autoritaria de algunos de los próceres tradicionales.

Desde el golpe de Estado de 1930, el avance de la influencia de la iglesia - que los liberales habían reducido drásticamente en la década de 1880 - y el protagonismo político de las Fuerzas Armadas - que desde ese año tomaron periódicamente por asalto el poder - favorecieron la presencia de una perspectiva autocrática en la interpretación del pasado. Así, se promovió la idea de que la salvaguarda de los valores patrióticos estaba depositada en una fuerte voluntad política del Ejército al servicio de una particular interpretación de los principios católicos.

Esta perspectiva no cambió con el nuevo golpe de Estado de 1943 - que dio un paso más en la influencia de la Iglesia al incorporar a la religión católica como materia obligatoria en las escuelas - ni tampoco cuando poco después, el General Perón fue elegido presidente. Pero cuando éste es derrocado, se abrió la última etapa del avance de la exaltación autoritaria sobre la historia patriótica.

Los enemigos de Perón azuzaron la polémica entre la "historia oficial" y el revisionismo histórico cuando en 1955 la introdujeron en la querella política de la época. El golpe cívico-militar que lo depuso se filió a la historia liberal al proclamarse los seguidores de la línea "Mayo-Caseros" - en referencia a la revolución que culmina con la declaración de la independencia y la batalla que pone fin al gobierno de Juan Manuel de Rosas - y calificaron al gobierno de 
Perón como la "Segunda Tiranía”, transformándolo así en una nueva versión de Rosas, que a la sazón resultaba el primer tirano. Perón nunca había sido revisionista antes de esta operación de sus enemigos, pero ante las nuevas circunstancias se acercó al revisionismo y sus partidarios crearon la línea histórica San Martín - Rosas - Perón, que unía a este último con los dos grandes exiliados de la historia nacionalista. Así, como sostiene Tulio Halperín Donghi en El revisionismo histórico (1970) los peronistas se hicieron revisionistas para oponerse a sus adversarios, pero también todos los revisionistas se convirtieron al peronismo y el revisionismo terminó transformándose en el "sentido común histórico". (Halperín, 1970)

Desde el derrocamiento de Perón y la proscripción de su partido, el país no pudo encontrar un nuevo equilibrio político. Los gobiernos civiles - carentes de legitimidad de origen al haber sido electos con la proscripción del peronismo - no conseguían estabilizarse y periódicamente eran desplazados por nuevos golpes militares que transformaron a los gobiernos autoritarios en un elemento más del folklore argentino. Pero la situación se agravó desde fines de la década del 60, a partir de las revueltas populares iniciadas con el "Cordobazo" y la aparición de las organizaciones guerrilleras, especialmente los Montoneros - de ideas peronistas - y el trotskista Ejército Revolucionario del Pueblo. Desde entonces el problema de una posible anarquía se instaló en la opinión pública como el peor de los males posibles y una nueva etapa de la exaltación del autoritarismo en la historia escolar se relacionó con este fenómeno.

Al tratar del proceso arriba mencionado, usted destaca en su libro algunas herencias de la enseñanza de la historia del período 1976-1993 que dan cuenta de la consolidación de un código disciplinar para la enseñanza de la Historia. Esta temática fue retomada en un artículo de 2011 publicado por la Revista Polihis, en el cual hace algunas consideraciones en relación a la formación inicial de los profesores de Historia en las universidades considerando la problemática de la esquizohistoria por un lado, y por otro la necesidad de reforzar las prácticas educativas pautadas por el valor formativo de la Historia y por la reafirmación de un compromiso con las temáticas relacionadas con los Derechos Humanos en el curso de esa formación.

Cuando hablo de esas "herencias" exagero un poco. Podríamos decir mejor que tanto en el gobierno militar de 1976-1983, la sangrienta dictadura que marcó un antes y un después en nuestra sociedad - como en el de la 
restauración democrática de 1983 a 1989 se encuentran algunos antecedentes de lo que a partir de 1993 buscará instaurar la reforma educativa. En el primer caso, la dictadura hace una reforma en 1979 de la enseñanza de la historia que se proponía un mayor control ideológico de los contenidos. En este caso, además de establecer la correlación entre la historia universal y la argentina que debían estudiarse en unidades separadas pero que trataban los mismos períodos correlativamente en cada uno de los cursos, se introducen dos novedades que anuncian lo que ocurrirá en los 90. La primera de ellas es que, producto de la paranoia de los militares, se le otorga más importancia a la historia del siglo XX. Este era un déficit de la enseñanza escolar y durante muchos años se sostuvo que los alumnos terminaban su educación secundaria sin sospechar que se había producido la Segunda Guerra Mundial. Esta novedad se explica por la idea de los dictadores acerca de que existían complots marxistas ocultos por todas partes y pensaron que era necesario reforzar el período de la Guerra Fría en la escuela para que los estudiantes estuvieran alertas ante un posible "lavado de cerebro" impulsado por el comunismo. A la vez, en las distintas facciones de los militares polemizaron internamente sobre casi todos los temas, el único en el que estuvieron de acuerdo en forma unánime era en que debían enfrentar a las organizaciones guerrilleras en un nuevo tipo de guerra, la "guerra sucia”, en la cual triunfaron con la crueldad conocida. También todos se ocuparon de subrayar que con esta victoria habían resguardado las mejores tradiciones del modo de vida argentino y evitado la disolución de la Patria. Con este propósito de exaltar el accionar de las Fuerzas Armadas es que se introduce por primera vez en esa reforma del currículum una narración (por supuesto apologética) de la represión en esos años. Estos dos temas, la historia del siglo XX y el pasado reciente, ocuparán el centro de la enseñanza a partir de la reforma educativa de los 90. La otra cuestión que señalo como antecedente es que en la transición democrática no hubo en la escuela secundaria un cambio en los contenidos de la asignatura pero sí en el tono que regía su convivencia y se buscó quitar el sesgo autoritario a la educación en general para incorporar pautas democráticas. Fue necesario incorporar temas como el funcionamiento de las instituciones constitucionales, el rol de los ciudadanos en un gobierno democrático, mejorar la convivencia participativa en las escuelas (por ejemplo, con el establecimiento de centros de estudiantes en las secundarias para fomentar la participación de los jóvenes), etc. Pero a pesar de que no hubo cambios inmediatos en la educación media (como sí la hubo en la 
universitaria), el gobierno del Dr. Alfonsín tenía la convicción de que la escuela necesitaba cambios profundos. Para ello convocó en 1984 a participar en el Segundo Congreso Pedagógico que debía definir los cambios que resultaban necesarios en la educación en una discusión amplia con la participación de todos los sectores interesados en el problema. Con esta denominación, Alfonsín buscaba filiar a este Congreso Pedagógico con el que se había reunido cien años antes y que había dado las bases de la educación que por mucho tiempo fue un motivo de orgullo para los argentinos. El resultado no estuvo a la altura de las expectativas, especialmente por los crecientes problemas políticos que debió enfrentar el presidente en otras esferas y se limitó a aprobar recomendaciones generales sobre los distintos temas. Pero, a pesar de ello, lo que yo sostengo es que esta iniciativa instaló en la opinión pública la necesidad de que un cambio profundo en la educación era imprescindible y prepara el terreno para la reforma de los 90. Claro que cuando esta se produzca no será, como planteaba Alfonsín, con acuerdos de base que irían subiendo hasta ser considerados por el Consejo Federal de Educación cuyas observaciones serían revisadas luego también por las bases en una segunda instancia, sino que será una reforma "desde arriba" impuesta por el Ministerio.

En su libro, al abordar lo que ha llamado "reforma de 1993" y que atañe a elementos centrales para la enseñanza de la Historia en la actualidad, usted da cuenta de lo que ha llamado "las carencias de la reforma".

La reforma de 1993 buscó cambiar totalmente la educación argentina en sus primeros niveles casi como si nada hubiera existido antes. En primer lugar hizo obligatoria la última mesa de educación inicial. En segundo término abolió los viejos niveles de enseñanza primaria (de siete años), que era obligatoria, y los reemplazó por la Escuela General Básica (de nueve años), que es la que resulta obligatoria desde 1993 y la Educación Polimodal (de tres), que era optativa. Así, el trayecto obligatorio pasa a ser de diez años. Pero además de estas cuestiones formales, se procura reemplazar los contenidos escolares, considerados para entonces totalmente obsoletos, por otros con los que se procura incorporar a la escuela saberes significativos en todas las asignaturas. Para lograrlo el Ministerio de Educación contrató en todas las disciplinas a especialistas que debían elaborar documentos que servirían como base para formular los nuevos contenidos. Este asesoramiento debía cumplir con ciertas normas: serían tres especialistas (profesores universitarios o investigadores 
reconocidos) por materia, al menos uno debía ser del interior del país (para evitar una perspectiva centrada en la ciudad de Buenos Aires) y cada uno de ellos debía consultar a otros diez académicos de su mismo nivel que él mismo elegiría para redactar su informe. Este sería el insumo más importante para redactar los nuevos contenidos pero la confección final con estos materiales quedaría a cargo de los equipos técnicos del Ministerio. En este paso se incorporarían una serie de criterios muy diversos en la redacción final de los nuevos temas. Una cuestión más que se agrega en esta reforma es el cambio en lo que se entendía como "contenidos": ahora debían aparecer explícitamente junto con los conceptos, los procedimientos que permitían llegar a esos conocimientos y los valores formativos que con ellos se procura producir en los jóvenes.

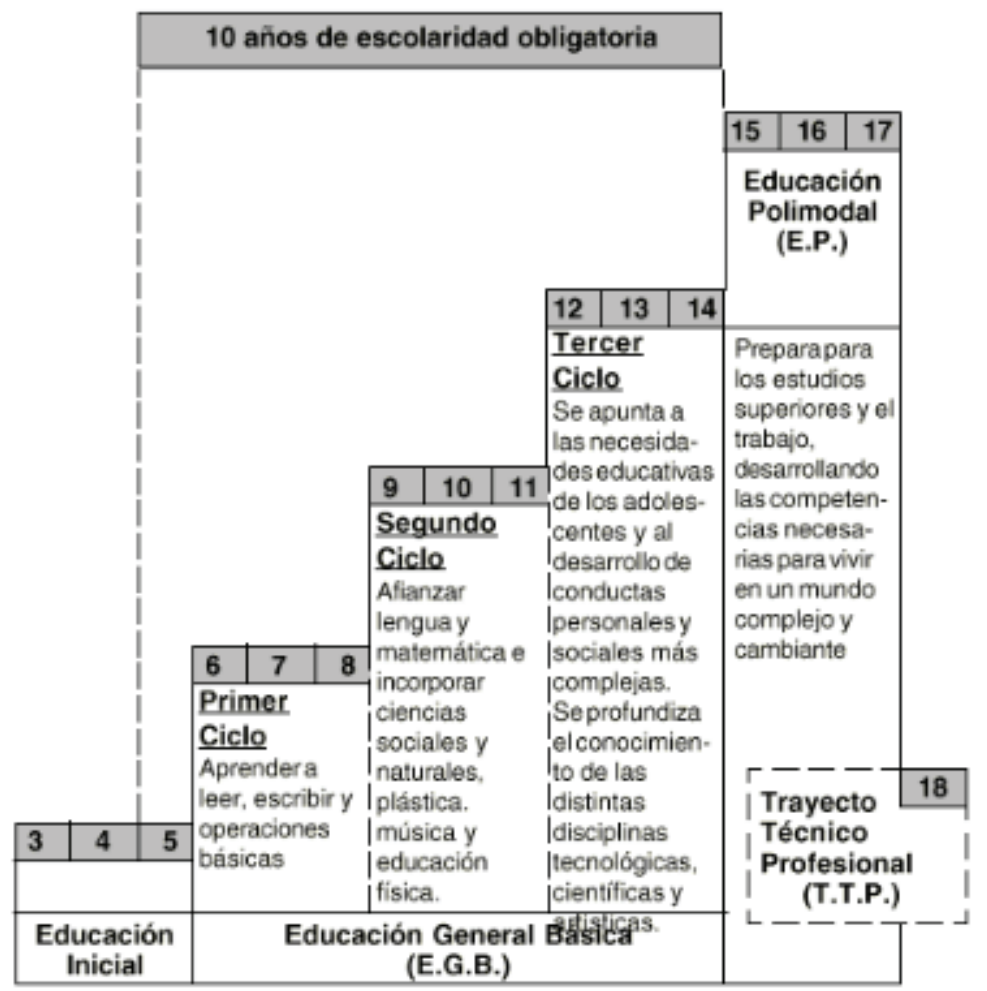

Figura 1 - Diseño del sistema de educación en Argentina después de la ley 24.195/1993, en vigor hasta 2006. 
La instrumentación de los cambios por los equipos ministeriales produjo diferentes distorsiones. En nuestro caso, una de ellas fue que en la EGB la historia dejó de ser enseñada como una disciplina independiente y se diluía en los últimos tres años de ese nivel en un área de ciencias sociales que incluía junto a ella a la geografía, la antropología, la economía, las ciencias políticas... Por otra parte, en Polimodal, la Historia recuperaba su individualidad pero su enseñanza se limitaba a los dos primeros años. Por otro lado, en esos dos años sólo se estudiaría la historia contemporánea. La idea era que conocer lo más cercano en el tiempo permitiría a los jóvenes entender mejor los problemas que les tocaba enfrentar en su presente, sosteniendo la arriesgada hipótesis de que todos los problemas actuales tienen un origen próximo en el tiempo. Esta hipótesis fue acompañada por otra que - aunque no era a principios de los años 90 el motivo de las innovaciones - se afianzó poco a poco hasta lograr una fuerza irresistible. Con el interés que tomó a partir de la segunda mitad de los años 90 el pasado reciente y las luchas por la memoria colectiva, el período preferido para la educación en valores se trasladó al estudio del nefasto período de la dictadura militar que gobernó de 1976 a 1983, considerado como inmejorable para formar un espíritu democrático y respetuoso de los derechos humanos en niños y jóvenes. Así fue como la educación ciudadana promovida en las clases de historia, que hasta entonces se basaba en la imitación de los héroes de la independencia, se modificó radicalmente.

A pesar de las buenas intenciones proclamadas por la "transformación educativa”, con el transcurso del tiempo se extendió en la opinión pública la percepción de que la educación en vez de mejorar se deterioraba y algunos sectores le adjudicaron a la reforma toda la responsabilidad de ese daño. Un aspecto particular de ese fracaso fue que no se logró conformar un sistema educativo federal integrado. En 1992 la Nación se desprendió de todas las escuelas secundarias y, de la misma forma que había ocurrido con las escuelas primarias durante la dictadura, todas ellas pasaron a depender de las distintas provincias en todos los aspectos financieros y educativos pasando así de un sistema centralizado a uno que resultó anárquico. Para ocuparse de ese estado de cosas, a fines de abril de 2004 el Consejo Federal de Cultura y Educación ${ }^{1}$ decidió por una resolución "núcleos de aprendizaje prioritarios" con el compromiso de realizar las acciones necesarias en el conjunto de las jurisdicciones educativas para que en todas ellas las personas tuvieran acceso a esos 
aprendizajes. En un documento del Ministerio de Educación de 2006 el fiasco se reconocía en toda su dimensión: "Nuestro punto de partida es un sistema educativo argentino que presenta un escenario sumamente heterogéneo y fragmentado ... Las distintas situaciones y experiencias escolares por las que transitan los niños y los jóvenes de nuestro país expresan un panorama de extrema desigualdad educativa que refuerza la injusticia social". ${ }^{2}$

A fines de 2006 se aprobó la Ley de Educación Nacional que dirigió el conjunto de sus disposiciones a eliminar gran parte de las innovaciones introducidas por la Ley Federal de 1993. Como consecuencia de la nueva normativa se eliminaron la EGB y el Polimodal para volver a niveles que volvían a su extensión previa al 93 y a denominarse otra vez primario y secundario, ampliándose nuevamente el trayecto educativo al disponerse que ambos ciclos serían desde entonces obligatorios. ${ }^{3}$

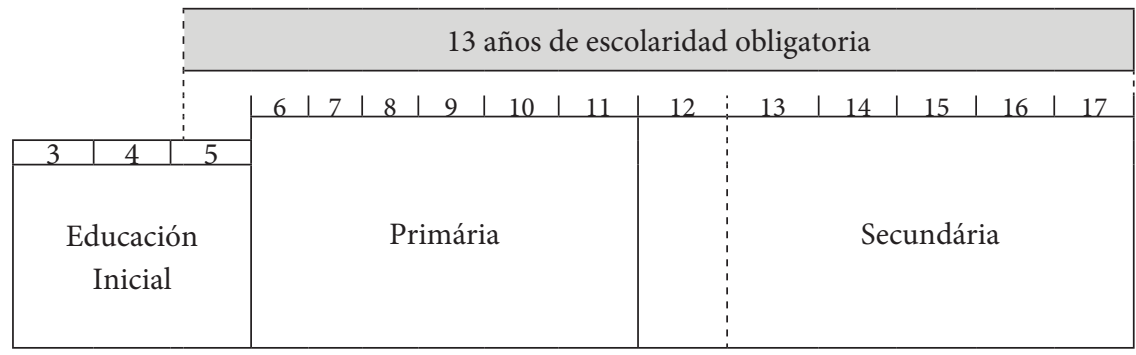

Figura 2 - Diseño esquemático del sistema educacional en Argentina después de la ley de Educación Nacional (2006). Es opcional a las distintas jurisdicciones dedicar 7 (siete) años al nivel primario y 5 (cinco) al secundario.

La nueva norma estableció la enseñanza de un segundo idioma, el acceso a las nuevas tecnologías de comunicación e información. La historia, por su parte, volvió a estudiarse como asignatura autónoma desde el segundo año de la escuela media. El propósito de los cambios introducidos en la normativa de 2006 era borrar la impronta neoliberal que se le adjudicaba a la "transformación educativa", doctrina que se consideraba como la razón de todos los males de la sociedad. La nueva normativa no se preocupó demasiado por renovar aspectos pedagógico-didácticos sino, sobre todo, por reorientar ideológicamente a la educación. Pero a pesar de los inconvenientes que había evidenciado la "federalización" educativa de los 90, la elaboración de los diseños curriculares continuó bajo la responsabilidad de las distintas provincias. Para atenuar 
los peligros de esa diversidad, la nueva ley estableció en uno de sus artículos algunos temas que debían de ser enseñados obligatoriamente en todo el país, en los cuales es perceptible el nuevo clima de época. Todos estos contenidos, de una manera u otra, se reflejarían necesariamente en las clases de Historia: el fortalecimiento de la perspectiva latinoamericana, especialmente de la región del Mercosur; ${ }^{4}$ la reivindicación de los derechos alegados por Argentina sobre Malvinas y otras islas del Atlántico Sur ${ }^{5}$ y "el ejercicio y la construcción de la memoria colectiva" sobre los gobiernos militares que atropellaron el orden constitucional y los derechos humanos. ${ }^{6}$ Asimismo se indicaba como necesario tratar los derechos de los pueblos originarios, los de niños y adolescentes y la igualdad de las mujeres. ${ }^{7}$

Algunos rasgos preexistentes en la enseñanza de nuestra materia se acentuaron. Una de estas características es el énfasis en la época contemporánea. A grandes rasgos, los contenidos que establecen los diseños curriculares más recientes en la provincia de Buenos Aires dedican primer año - el único donde el pasado se incluye en un área de ciencias sociales - a la aparición del hombre, la Edad Antigua y la Medieval; segundo año a la Edad Moderna hasta la Revolución industrial y la Revolución Francesa - o sea, según Hobsbawm, la "doble revolución" que origina el mundo actual -; el tercero al siglo XIX; cuarto a la primera mitad del siglo XX y quinto a su segunda mitad. En todos los casos se incluyen temas de historia argentina, latinoamericana y universal. Para dos especialidades - Artes y Ciencias Sociales - hay un año más de historia, dedicado a la investigación de la historia argentina reciente (las décadas del 70, 80 y 90 del siglo pasado) en el curso final de la secundaria.

\section{En la segunda parte del libro publicado en 2008, intitulada "Entre la historia} y la enseñanza" destaca que la enseñanza de la Historia no es una simple consecuencia de los conocimientos que los docentes poseen de su disciplina.

Aunque en Argentina la formación de profesores siempre resultó un asunto espinoso, se ha transformado en un tema especialmente polémico en los últimos veinte años. Una de las razones de esta controversia es que desde la reforma educativa de los años 90, los saberes disciplinares que los docentes deben desplegar en sus clases de historia se modificaron profundamente cuando se procuró actualizar los contenidos de esa asignatura en la escuela, que desde entonces presentó cambios significativos en los diseños curriculares cada 
cuatro o cinco años. Pero los problemas en la preparación de educadores no se agotan en la renovación de los conocimientos ni son únicamente locales porque los diferentes procesos de cambio social producidos en el mundo hicieron que los requerimientos para su desempeño resulten más complejos en muchos sentidos. Los docentes están llamados hoy a ejercer su trabajo con mayores niveles de autonomía, mayor capacidad de trabajar en equipo, un dominio disciplinar que los habilite para no tener respuestas únicas y un fuerte compromiso ético, social y técnico con los resultados de aprendizaje de sus alumnos. Es en este contexto que muchos países implementaron modificaciones en su formación.

$\mathrm{Al}$ analizar esos diferentes cambios puede apreciarse una tendencia a incrementar la duración de las carreras y, en muchas partes, a llevar estos estudios al nivel universitario. En el continente europeo, esa corriente podría describirse con un arco que va del traspaso en Finlandia de toda la preparación referida a la enseñanza al ámbito universitario en los años 70 a la decisión en España de crear en 2010 una maestría que debe cursarse obligatoriamente para ejercer como profesor, luego de terminar la licenciatura en la disciplina que se pretende enseñar. Sin embargo, aparece una inclinación inversa en otros lugares como Estados Unidos e Inglaterra, naciones donde las escuelas universitarias de educación suelen criticarse por demasiado teóricas y alejadas de la realidad del aula.

En el caso argentino existe una superposición de estas dos lógicas y la preparación de profesores se realiza tanto en instituciones universitarias como en otras no universitarias, en una organización muy compleja que se ha ido consolidando a través del tiempo. Por un lado, la mayor proporción de los jóvenes que definen su vocación por la enseñanza concurre a institutos terciarios no universitarios donde, en términos generales, los planes de estudios están centrados en los contenidos pedagógicos mientras que la formación disciplinar específica resulta más débil. Por su parte, las universidades también forman desde sus inicios profesores y allí la lógica de la preparación se invierte: existe en ellas un fuerte énfasis en los contenidos disciplinares y una formación pedagógico - didáctica que demanda menos horas de estudio. El censo docente que se realizó en 1994 mostró la extraordinaria diversidad de esa formación, con distintos tipos de instituciones terciarias de gestión privada y pública que dependían de diferentes jurisdicciones y con proyectos que podían resultar 
muy diversos. Según este censo ${ }^{8}$ existían entonces 1122 institutos no universitarios con una gran concentración en las provincias de Buenos Aires (312), Córdoba (122), Santa Fe (95), Entre Ríos (61) y la Capital Federal (69). El 36\% de todos ellos era de gestión privada. El panorama se completaba con el también complejo ámbito de las universidades, que no sólo preparaban docentes para el ciclo secundario, sino que algunas de ellas tenían carreras para educación inicial, básica y especial. En 1994 eran cuarenta y dos las instituciones universitarias que preparaban profesores de los diversos niveles, de las cuales catorce eran privadas. Veinte años después, el número de las instituciones tanto universitarias como no universitarias se ha incrementado aún más.

Ante esta situación, a fines de los 1990 el Ministerio de Educación promovió acortar las diferencias en la formación en institutos y universidades fortaleciendo los puntos débiles en cada uno de los casos. En lo referido a las universidades se estableció que para mejorar las competencias pedagógicas debía destinarse un mínimo del 30\% del tiempo del curriculum a los fundamentos de la profesión docente (pedagogía, psicología educacional, didáctica general, entre otros). Esas iniciativas de cambio abrieron un amplio debate y las decisiones fueron diversas en las distintas casas de altos estudios. En uno de los extremos, la Universidad de Buenos Aires interpuso un recurso de amparo y paralizó por vía judicial cualquier tipo de cambio en sus carreras, lo que incluyó a la formación docente. En el otro, algunas universidades - como, por ejemplo, las de La Pampa y Cuyo - se adecuaron al porcentaje exigido. En este último caso, el dilema para acomodarse a ese $30 \%$ consistía en si debían eliminarse materias de los saberes sustantivos de las disciplinas para reemplazarlas por otras dedicadas a temas pedagógicos - lo que hubiera transformado a la formación universitaria en profesorados light en los conocimientos disciplinares - o agregar tantas asignaturas de pedagogía como fueran necesarias para alcanzar aquella proporción. En todos los casos en que se optó por la adecuación a las demandas ministeriales se eligió esta última variante, lo que se tradujo luego en graves inconvenientes al tener como consecuencia el alargamiento de la duración real de las carreras.

Hubo también otras propuestas. Desde la Facultad de Humanidades de la Universidad de La Plata se cuestionó el criterio exclusivamente cuantitativo implícito en el porcentaje demandado para la formación pedagógica y se propuso, además, que los contenidos de las asignaturas que componían ese bloque 
debían ser repensados para que resultaran significativos en la preparación de los futuros docentes - lo que muchas veces no ocurría - y que recién luego de esa reformulación podría determinarse cuál debía ser su proporción en la totalidad del curriculum. Cumplidos estos pasos, se presentó en 1998 una solicitud al Ministerio de Educación para que el Consejo Federal bajara al 20 \% la exigencia mínima de estos contenidos en las carreras de profesorado. El reclamo recibió la adhesión de otras diez facultades de universidades nacionales y, con una fórmula más amplia, fue incluido en el programa de la Asociación Nacional de Facultades Ciencias Sociales y Humanidades (ANAF). Un resultado inesperado de esta controversia fue que, como consecuencia de las intenciones ministeriales de homogeneizar la formación docente, la heterogeneidad entre las distintas universidades aumentó, ya que al seguir distintos criterios para adecuarse a aquellas exigencias se incrementaron las diferencias en el número de materias que atendían a los saberes pedagógicos y didácticos.

La crisis de 2001 interrumpió este debate y en las universidades se abrió una especie de tregua acerca de la manera de introducir cambios en la formación de profesores, una paz precaria que se quebró cuando a fines de 2006 fue sancionada la Ley de Educación Nacional. La nueva normativa intentó otra vez disminuir la heterogeneidad mediante la creación del Instituto Nacional de Formación Docente. En este nuevo organismo se aprobaron una serie de estándares que deberían cumplir todas las carreras que preparan profesores para que fueran evaluadas positivamente y sus títulos tuvieran validez. Luego de un período inicial de confusión, se aclaró que estas directivas - que promovían un significativo predominio de los saberes pedagógicos - no alcanzaban al ámbito universitario pero que las universidades deberían establecer también parámetros para sus profesorados y que esas carreras serían evaluadas. Desde 2010 las facultades con profesorados en historia, geografía y letras discuten en la Asociación Nacional de Facultades de Humanidades y Educación (ANFHE) cómo deben adecuar sus trayectos docentes a las nuevas exigencias, en un proceso que en la carrera de historia ha sido trabajoso y en ocasiones conflictivo.

Uno de los resultados de este trabajo fue la puesta en evidencia de las grandes disparidades que presentan entre sí los profesorados de historia de las universidades nacionales. Analizando veintitrés casos la ANFHE comprobó esa heterogeneidad. Algunas de esas conclusiones fueron que: 
1. Aunque todos los títulos de profesor en historia preparan para enseñanza media y superior, algunos aún se expiden para niveles educativos hoy inexistentes (EGB y polimodal), ya que han sido modificados por la Ley de Educación Nacional.

2. En la mayoría de las universidades existe una fuerte tendencia a la articulación entre las dos carreras de Historia - profesorado y licenciatura - pero no hay un criterio común en la duración de los profesorados: de los 23 casos analizados, 8 tienen planes de 4 años de duración; 14 de 5 años y uno de los planes tiene una extensión de 4 años y medio.

3. Tampoco hay un criterio común en la carga de la carrera en horas reloj: 16 planes tienen más de 2860 horas, mientras que 7 presentan una duración inferior a ese parámetro.

4. Además, en ninguno de los casos el cursado teórico de la carrera - sea más largo o más corto - coincide con su tiempo efectivo de duración, que las estadísticas revelan en todos los casos como mucho mayor.

5. Respecto a los años en que fueron aprobados los planes de estudios en vigencia en las universidades analizadas, la mayoría de ellos son previos a la Ley de Educación Nacional. Sólo cuatro instituciones de las consideradas desarrollan sus carreras con planes posteriores al 2006 (Catamarca, La Pampa, La Plata y General Sarmiento). ${ }^{\text {}}$

Estas diferencias fue uno de los motivos por los que la discusión lleva ya cinco años sin resultados definitivos pero la demora no se debe sólo a esto. Como todos sabemos, cada vez que se producen situaciones de este tipo se mezclan en los debates una serie de asuntos adicionales entre las universidades como viejos resquemores, la defensa de intereses particulares, las distintas percepciones sobre la repercusión política que tendrían los cambios al interior de cada institución y muchas cuestiones más.

En conclusión, es un tema que no se solucionará a corto plazo y cuyas controversias son tanto políticas (en un sentido amplio) como académicas y, en la mayoría de los problemas, ambas cuestiones aparecen imbricadas. Desde el punto de vista académico creo que sería necesario discutir qué es enseñar historia en la escuela. Tradicionalmente, la historia escolar procuraba que los alumnos conocieran y memorizaran los principales acontecimientos del 
pasado y que estos saberes sirvieran de ejemplo para transformarlos en buenos ciudadanos.

Esta perspectiva se ha renovado y en los últimos tiempos se ha difundido el concepto de "educación histórica". Pero estas ideas no sólo no se discuten en Argentina sino que resultan casi desconocidas. En este nuevo criterio se privilegia a la Historia desde sus particularidades como una disciplina que constituye una forma de conocimiento específico, con su propia lógica y su metodología. En definitiva, una actividad intelectual que permite un acercamiento a los problemas de la sociedad distinto al que proporcionan otras materias escolares y que posibilitaría que niños y jóvenes puedan orientar las decisiones individuales y colectivas de su vida práctica mediante la utilización de las herramientas que brinda la Historia. Esta finalidad implica un posicionamiento diferente frente al pasado porque en vez de recibir ejemplos de los próceres del pasado se procura desarrollar una actitud crítica basada en no aceptar ideas, informaciones o datos sin tener en cuenta el contexto - social, político, cultural y temporal - en que fueron producidos, analizar los argumentos empleados por sus autores, examinar las pruebas ofrecidas para sostener esos argumentos, etc.

Desde mi punto de vista, la cuestión central acerca de la formación docente está implícita en una innovación teórica posiblemente no advertida por todos, acerca de lo que es la didáctica de la historia. El concepto predominante hasta ahora ha sido el de "didáctica especial" que postula que se debe lograr un modelo de transmisión común para que los conocimientos de cada una de las distintas disciplinas puedan ser comprendidos por los niños y los jóvenes. En este caso, el problema de la didáctica como ciencia es encontrar la forma apropiada de comunicar un conocimiento que es externo a ella, sea la historia, la matemática, la filosofía o la física. La didáctica es, en este caso, sobre todo un problema de las ciencias de la educación. Pero cuando se habla de "didácticas específicas" se entiende, en cambio, que cada una de las disciplinas tiene una lógica y características singulares cuya enseñanza no depende de un modelo general para transmitir ese conocimiento. Los problemas de la enseñanza son considerados en este caso como dificultades propias de la misma ciencia que se pretende enseñar. En nuestro caso, desde las particularidades de la Historia como una disciplina que constituye una forma de conocimiento específico y, 
por lo tanto, para pensar en su enseñanza resultaría necesario partir del conocimiento histórico.

Esta situación, entonces, promueve un conflicto cuyas consecuencias internas todas las instituciones involucradas prefieren evitar.

En su libro se abordan algunas cuestiones que, en la actualidad, siguen siendo polémicas y provocando reflexiones académicas. Ellas son:

a) ¿Es conveniente continuar enseñando Historia utilizando exclusivamente un tiempo histórico lineal?

b) ¿Pueden los niños y jóvenes comprender el pasado remoto?

c) ¿Quiénes son los protagonistas de la historia y cómo se los puede estudiar en el aula?

d) ¿Qué resultados se pueden vislumbrar cuando en el aula trabajamos de manera análoga a la del historiador para enseñar a nuestros alumnos a pensar históricamente?

La imposibilidad de que los niños y los jóvenes comprendan un pasado remoto es la herencia de la afirmación de los psicólogos educacionales piagetianos a fines de los años de la década de 1950, cuando sostuvieron que los jóvenes podían comprender en la escuela las ciencias exactas pero no la historia antes de los dieciséis años, porque para entenderla necesitaban una mayor maduración y haber entrado en el estadio del pensamiento lógico formal lo que, según ellos, recién se producía cuando se alcanzaba esa edad. Esta afirmación prácticamente inhabilitaba la enseñanza escolar de la Historia y produjo una profunda impresión en su momento, pero nunca pudo ser demostrada científicamente. Más aún, psicólogos de esa misma corriente admitieron más adelante que la edad en la que se entraba en el pensamiento lógico-formal variaba notablemente según las particularidades socioculturales de cada grupo humano y que, aún, había individuos que nunca alcanzaban ese estadio. Sin embargo, esta idea persistió en el sentido común de los profesores, posiblemente porque les brindaba una explicación para las dificultades de comprensión de sus alumnos. En términos que podemos vincular con este problema (y que nos permite, además, inferir la "modernidad" de las objeciones de este tipo), podemos recordar lo que Hegel decía el 2 de septiembre de 1811, en el discurso de fin de curso del Gymnasio que dirigía en Nüremberg: 
Constituye uno de los prejuicios, que han sido difundidos por la moderna Ilustración ... que a la juventud no se le han de inculcar tempranamente conceptos y principios morales ni tampoco doctrinas religiosas debido a que ella no los entiende y a que sólo almacena palabras en la memoria. Pero considerada la cosa con más precisión, es fácil observar que los conceptos éticos pueden ser bien comprendidos, en consonancia con su edad, por el niño, por el muchacho y por el joven, y que toda nuestra vida no es otra cosa que aprender a comprender de una forma cada vez más profunda su significado y su extensión, en verlos reflejados mediante ejemplos continuamente renovados y sólo así conocer, de una forma cada vez más detallada, la gran amplitud de su sentido, el carácter determinado de su aplicación. De hecho, si se quisiera esperar, para familiarizar al hombre con esta temática, hasta que fuera completamente capaz de percibir los conceptos éticos en toda su verdad, pocos llegarían a poseer esta capacidad, y estos pocos apenas lo lograrían antes del final de su vida. Sería la falta misma de reflexión ética la que retrasaría la formación de esta capacidad perceptiva así como la del sentimiento ético. Ocurre con esto lo mismo que con otras representaciones y conceptos, cuya comprensión comienza asimismo por un conocimiento no comprendido, y sería lo mismo que si se exigiese que sólo un general hubiera de conocer la palabra batalla, dado que sólo él sabe verdaderamente lo que es una tal. ${ }^{10}$

Creo que en el tema de las civilizaciones remotas en el tiempo y el espacio podemos pretender algo parecido: que se vayan comprendiendo esos temas con una complejidad creciente en relación con la edad de los alumnos.

En el resto de las cuestiones, me parece que es conveniente buscar un equilibrio entre las necesidades de la disciplina histórica y las posibilidades didácticas. El caso del tiempo lineal es un ejemplo de ello. Por una parte, debemos prestar atención a este problema porque sabemos que la comprensión de la Historia depende de tener en claro qué sucedió antes y qué sucedió después. En este sentido, entonces, no podemos desentendernos de las dificultades que la cronología le presenta a los alumnos. Pero también es necesario introducir una consideración más compleja del tiempo histórico que se visualiza, básicamente en dos tipos de actividades. Por una parte, mediante el estudio de problemas presentes en su dimensión histórica. La estrategia consiste en delimitar un problema social de actualidad (por ejemplo, aluvión inmigratorio de medio Oriente a Europa o la corrupción política en América Latina), establecer sus relaciones con otras esferas de lo social (es decir, con su contexto); captar su carga temporal; su proceso; desde cuándo existe; qué pasó a lo largo de los 
años, cómo se agudizó o se solucionó y por qué. Por otra, haciendo una nueva utilización de las fechas al elaborar mapas con conceptos complejos: coyuntura política, relaciones temporales y cambios y movimientos a lo largo de un determinado proceso histórico.

En lo que se refiere a los protagonistas de la Historia, la escuela argentina se mantuvo por más de cien años centrada en los próceres, especialmente los de la independencia, y de la imitación de sus acciones. La crítica a la historia heroica fue una bandera de quienes buscaban "desmilitarizar" la educación y la cultura. Una cuestión interesante en este propósito fue la alteración de la idea tradicional cuando desde 2006 se incluyó en el calendario escolar al Día de la Memoria, la Verdad y la Justicia que desde entonces evocó las atrocidades del régimen militar instaurado desde el 24 de marzo de 1976. La conmemoración del 24 de marzo invierte dramáticamente el modelo de la historia ejemplar: hay que recordar las acciones miserables y despiadadas de los dictadores para aprender a no repetir ese pasado vergonzoso. Esta modificación de las reglas ponía a la escuela en tensión pero no solucionó el problema. Es cierto que hoy la historia es algo muy diferente de la psicología y las acciones heroicas de los padres de la Patria - todos hombres blancos pertenecientes a la burguesía criolla que se movían en un escenario en el que no aparecían actores diferentes en clase, etnia o género. Aún hoy, cuando leemos los manuales escolares, no encontramos en las páginas de los manuales argentinos - más que ocasionalmente - a mujeres, indios o negros. Los cambios introducidos en los últimos veinte años en los diseños curriculares privilegian el estudio de los procesos históricos en desmedro de los acontecimientos, pero - desde mi punto de vista - no se ocupa lo suficiente de que para comprenderlos en la escuela es necesario encarnar esos procesos en seres humanos concretos. El "proletariado" es una categoría sociológica, los que realmente existen son los obreros de carne y hueso y en ellos deberíamos centrar nuestras explicaciones de la industrialización. Podríamos pensar que la "historia desde abajo" y la "historia de género" puede resultarnos útil para crear una nueva narración escolar del pasado. Pero este objetivo no es fácil. En una investigación que estamos desarrollando ${ }^{11}$ y que incluye a investigadores que trabajan en Argentina, Brasil, Chile, Paraguay y Uruguay nos encontramos con que, en todos esos países, los alumnos declaran que no les interesa el pasado de la gente corriente. Este 
obstáculo tal vez se deba a una supervivencia del código disciplinar, para el que la Historia sólo se debe ocupar de la gente "importante".

Por último, desarrollar en nuestros alumnos habilidades análogas a las que desarrollan los historiadores - lo que hace unos años se denominaba como "contenidos procedimentales" - debiera ser prioritario. Si lo que buscamos es enseñar a pensar históricamente es imprescindible presentar a los jóvenes problemas, cuestiones no resueltas. Pueden plantearse preguntas históricas a partir del presente, usando los problemas contemporáneos como generadores de esos interrogantes, tal como lo hace el historiador. Esto permitirá establecer relaciones entre conocimientos anteriores y las nuevas informaciones, encontrar contradicciones, cuestionar las informaciones y las fuentes, plantear hipótesis... Este tipo de trabajo, en mi opinión, desarrolla el pensamiento crítico y lleva a una concepción más matizada de la realidad histórica. Uno de los principales problemas de la historia escolar es que instaló en el sentido común que todo lo que nos pasa se debe simplemente a que nuestros gobernantes son "buenos" o "malos", toda nuestra desdicha o nuestra felicidad se debe al resultado de sus acciones premeditadas y su catadura moral. Graham Greene decía más o menos lo siguiente: "Las cosas nunca están entre el negro y el blanco, siempre están entre el negro y los grises". Es una frase que algunos pueden considerar escéptica y otros (como es mi caso) realista, Pero que para mí es un ejemplo bastante bueno de que la historia escolar nos debería enseñar a descubrir los matices.

Ahora bien, si este tipo de trabajo me parece tan importante, en la misma investigación que comenté nos encontramos con datos bastante descorazonadores: a pesar del impulso que se le dio a los "procedimientos" en estas últimas dos décadas, en las aulas de todos los países considerados predomina un aprendizaje de la historia que se realiza en altísimo grado mediante las exposiciones de los profesores y la lectura de los textos escolares o materiales similares. En otras palabras, una enseñanza muy parecida a la de fines del siglo XIX.

\section{REFERÊNCIAS}

AMÉZOLA, Gonzalo de. Esquizohistoria: la historia que se enseña en la escuela, la que preocupa a los historiadores y una renovación posible de la historia escolar. Buenos Aires: Libros del Zorzal, 2008.

. Historia enseñada e historia investigada: relaciones peligrosas. El tratamien- 
to escolar de la última dictadura militar y la necesidad de una actualización académica en la formación de professores. Revista Polhis, n.8, p.9-26, $2^{\circ}$ sem. 2008.

HEGEL, G. W. F. (1991). Escritos pedagógicos. Madrid: Fondo de Cultura Económica, 1991.

\section{NOTAS}

${ }^{1}$ El Consejo Federal de Educación está integrado por los ministros del área de todas las jurisdicciones educativas y el Ministro de Educación de la nación. En este organismo se acuerdan medidas para aplicar a nivel nacional.

${ }^{2}$ Ministerio de Educación, Ciencia y Tecnología de la Nación. Núcleos de Aprendizajes Prioritarios. Tercer Ciclo EGB/Nivel Medio. Ciencias Sociales, 2006. p.7.

${ }^{3}$ En virtud del federalismo se habilita a que si alguna jurisdicción lo prefiere dedique siete años a la primaria y cinco a la escuela secundaria.

${ }^{4}$ Ministerio de Educación, Ciencia y Tecnología. Ley de Educación Nacional, 2006. Art. 92, inc. a. P. 32.

${ }^{5}$ Ibidem, art. 92. inc. b.

${ }^{6}$ Ibidem, art. 92 inc. c.

${ }^{7}$ Ibidem, art. 92 incs. d, e y f.

${ }^{8}$ Ministerio de Cultura y Educación (1998) Censo Nacional de Docentes y Establecimientos '94. Buenos Aires.

${ }^{9}$ Cfr. Acta de la Comisión Interinstitucional de las carreras de Profesorados en Historia, de la Asociación Nacional de Facultades de Humanidades y Educación (ANFHE) del $12 / 4 / 2012$.

${ }^{10}$ HEGEL, 1991, p.102-103.

${ }^{11}$ Este es el proyecto "Jovens e a História no Mercosul”, citado.

Entrevista recebida em 28 de outubro de 2015. Aprovada em 20 de novembro de 2015. 